\title{
Intelligent MSW Biocell Approach for Efficient Methane Production
}

\author{
Ahmad Qasaimeh \\ Department of Civil Engineering, Faculty of Engineering, Jerash University, Jerash, Jordan \\ Email: argg22@yahoo.com
}

Received May 7, 2012; revised June 20, 2012; accepted July 10, 2012

\begin{abstract}
The aim of this research is to provide approach to enhance methane production and to convert $\mathrm{CO}_{2}$ released into methane via anaerobic degradation. Despite $\mathrm{CH}_{4}$ has more global warming potential than $\mathrm{CO}_{2}$ but it is less available in the environment and it has fuel value. This research suggests approach that methane is being stimulated and carbon dioxide is being converted to methane. The methane enhancement herein is achieved via technical and intelligent processes. The technical processes entail leachate and carbon dioxide recirculation. The re-circulated leachate is controlled via fuzzy intelligent system that acquires values of abiotic factors such as C:N:P, $\mathrm{pH}$, temperature, and moisture content, and then these values are introduced to trained fuzzy system to decide the value of methane production quality. The fuzzy logic proceeds in systematic sequence as input, inference through rules, and output. If the fuzzy logic output decision indicates bad production, then the value of aboitic factors are dynamically altered with optimized combination of values. Carbon dioxide is being re-circulated in order to convert it biologically to methane by hydrogenotrophic methanogens. The hydrophobic permeable membranes are used as planes through the solid waste. These selective membranes are used to separate biogas and to have smooth and fast transfer of biogas from waste to the storage. The approach of this research is believed to be as a new generation of sustainable green bio-fuel biocells.
\end{abstract}

Keywords: Intelligent; Enhanced $\mathrm{CH}_{4}$ Production; $\mathrm{CO}_{2}$ Conversion; Leachate Recirculation; Abiotic Factors; Hydrophobic Membranes

\section{Introduction}

The storage of municipal solid waste (MSW) in landfills contributes to the green house gas (GHG) effect. Methane $\left(\mathrm{CH}_{4}\right)$ gas is one of the most important GHGs because of its fuel value and because it's global warming potential is more than 20 times carbon dioxide $\left(\mathrm{CO}_{2}\right)[1]$. Atmospheric $\mathrm{CH}_{4}$ gas has more than doubled in concentration over the last 150 years [2]. Landfill gas is formed during the decomposition process of waste organic content under anaerobic conditions. It consists of $60 \% \mathrm{CH}_{4}$, $40 \% \mathrm{CO}_{2}$ by volume and others trace amount $[3,4]$. Therefore, $\mathrm{CH}_{4}$ and $\mathrm{CO}_{2}$ gases are considered the main end products of solid waste biodegradation under anaerobic conditions.

Leachate recirculation is one option for inexpensive leachate disposal and for reducing the cost of post-closure care and long-term liability [5,6]. It could participate to improve leachate quality; reduce volume of leachate to be treated; and enhance gas production [7]. leachate recirculation reduced waste stabilization time and was effective in enhancing gas production and improving leachate quality, especially in terms of COD (Chemical
Oxygen Demand). Leachate recirculation has a positive effect on $\mathrm{CH}_{4}$ formation [8].

Landfill gas production rates are influenced by local and environmental parameters such as the abiotic factors, as well as landfill operation procedures [9]. The abiotic factors can be summarized as: $\mathrm{pH}$, nutrients, inhibitors, temperature, and water content, while the landfill operation procedures can be summarized as: waste composition, sewage sludge addition, shredding, compaction, soil cover, recirculation of leachate, and pre-composting.

The methanogenic bacteria operate only within 6 - 8 $\mathrm{pH}$. Anaerobic ecosystem requires much less nitrogen $\left(\mathrm{N}_{2}\right)$ and phosphorous $(\mathrm{P})$ than the aerobic system. The optimal ratio for organic matter (express as chemical oxygen demand; COD), $\mathrm{N}_{2}$ and $\mathrm{P}$ content, is 100:0.44: 0.08 [9]. Nutrients and metal supplementation have a positive effect on biogas production rate [10].

The active temperature for methanogenic microorganisms is in the range $30^{\circ} \mathrm{C}-50^{\circ} \mathrm{C}$. The temperature for mesophilic bacteria is in the range $30^{\circ} \mathrm{C}-35^{\circ} \mathrm{C}$, while $45^{\circ} \mathrm{C}-65^{\circ} \mathrm{C}$ is for the thermophilic bacteria. The optimum temperature range of gas generation is between $30^{\circ} \mathrm{C}-45^{\circ} \mathrm{C}$ during the main landfill gas generation 
phase [11]. The change of temperature will have an impact on the growth of biomass and the activity of the microorganisms [12].

The range of moisture content in a typical landfill is 15 to $40 \%$ with a typical average $30 \%$ [11]. Some studies have indicated that refuse samples containing greater than 55\% (wt/wt) moisture content produced increased amounts of $\mathrm{CH}_{4}$ while those that contained less than 33\% moisture content did not produce $\mathrm{CH}_{4}$ [13]. The rate of gas generation increases with the increment of moisture in landfill site [14]. The water content in landfill sites assists to exchange of substrate, nutrients, buffer, and dilution of inhibitors and spreading of microorganisms [15].

\section{The Approach}

The municipal solid waste is considered now a days as a source of energy. In this article, design of anaerobic biocell reactor to utilize MSW is supposed. The approach herein is to make use of hydrophobic selective membrane for efficient collection and separation of biogas. For methane production enhancement; $\mathrm{CO}_{2}$ is planned to be re-circulated to convert it for methane. Furthermore; to enhance methane production, methanogens is planned to be stimulated by optimizing abiotic factors such as: moisture content, nutrients, $\mathrm{pH}$, and temperature via control on leachate recirculation. In technical virtue, $\mathrm{pH}$ and nutrients can be fixed at typical value for methane enhancement. Consequently, temperature and water content are variables throughout the year during seasons, and thus intelligent fuzzy system has been applied to the MSW biocells design.

\section{Intelligent MSW Biocells: Design and Operation}

In our anaerobic biocell approach (Figure 1), methane production can be controlled via technical processes that affect the kinetics of methane production. The biocell is designed with layers of selective permeable hydrophobic membrane planes built through the solid waste for efficient biogas collection and separation. Permeable hydrophobic polymer has been investigated in previous research works conducted by the author [17-21]. Still, in the area of biotechnology, selective membranes have potential beneficial application to separate gases. Methane production can be controlled via technical processes that affect the kinetics of methane production. One technical process is to re-circulate carbon dioxide to be converted for methane by biological conversion. The biological conversion of $\mathrm{CO}_{2}$ to $\mathrm{CH}_{4}$ is achieved by hydrogenotrophic methanogens. One of the advantages of this technology over chemical conversion is that it requires much lower energy for reduction of $\mathrm{CO}_{2}$. The ratio of $\mathrm{CO}_{2}: \mathrm{H}_{2}$ is an important factor in determining the conversion rate of $\mathrm{CO}_{2}$. The $\mathrm{H}_{2}$ is a product released during acidogenesis and acetogenesis processes.

Other technical process is to collect leachate and re-circulate it for treatment and for enhanced methane production. The leachate is controlled by intelligent system for optimizing abiotic parameters. The parameters that are controlled are: moisture content, nutrients, $\mathrm{pH}$, and temperature. These parameters are acquired by sensors and then they are fed to learned fuzzy logic system to decide the quality of methane production (Figures 1 and 2). Intelligent fuzzy logic system is trained with

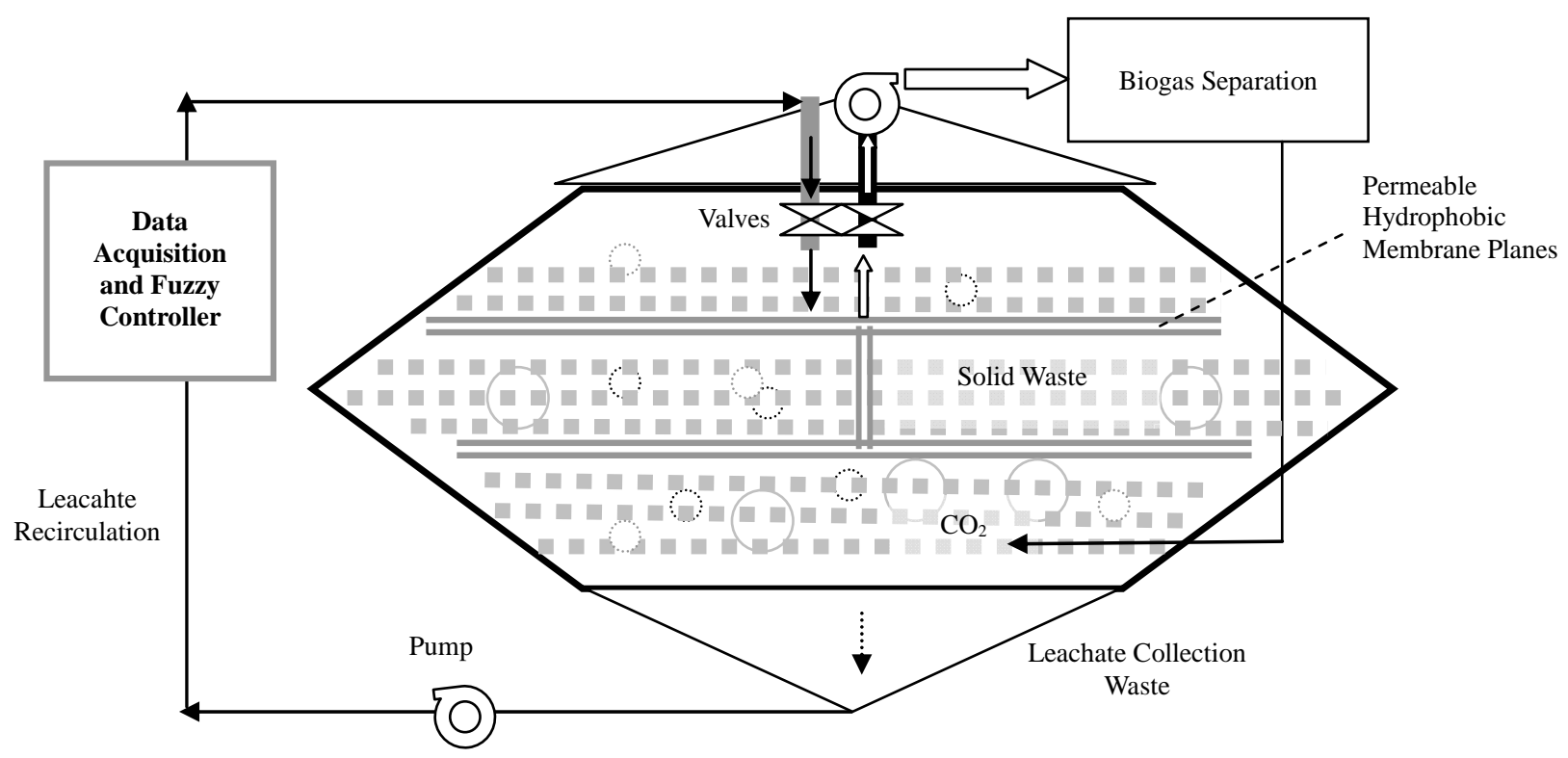

Figure 1. Approach of intelligent MSW biocell system. 
available experience about the methane production and the effect of abiotic factors on methane production. The fuzzy system is constructed as input premises (the abiotic factors), rules, inference system, and output values of the degree of methane production. As shown in Figure 3, intelligent fuzzy logic system acquire data about abiotic parameters and then introduce input values for trained fuzzy model to get output result of methane production quality. If methane produced is bad or moderate, then the acquired data are scanned to find lacked parameters and adjust them, then a new process of fuzzy decision for new parameters value is achieved. Hence the process is being optimized by simultaneous and dynamic fuzzy intelligent control.

However, some parameters can be technically fixed at typical value such as: C:N:P ratio of 200:4.5:1, and $\mathrm{pH}$ of 6 - 8 other parameters such as moisture and temperature are variable that are changing throughout the year different from summer to winter conditions. Moisture usually exerts strong control over $\mathrm{CH}_{4}$ production rates; also inclusion of both moisture and temperature in models can increase predictive capabilities. The strong relationship

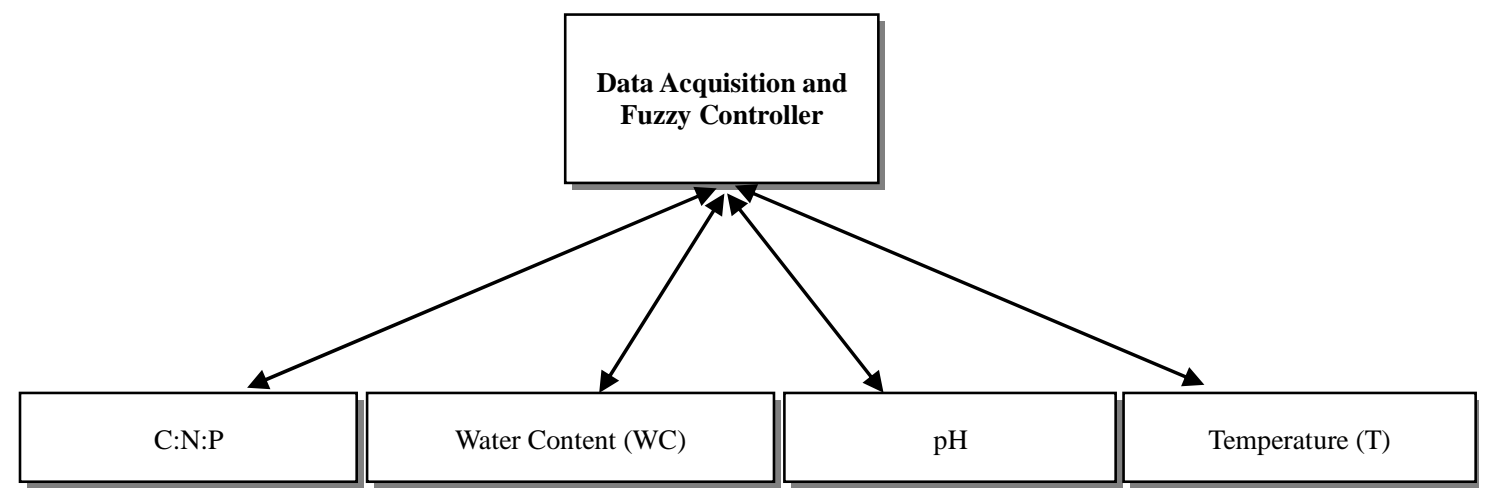

Figure 2. Data acquisition and fuzzy control on abiotic factors.

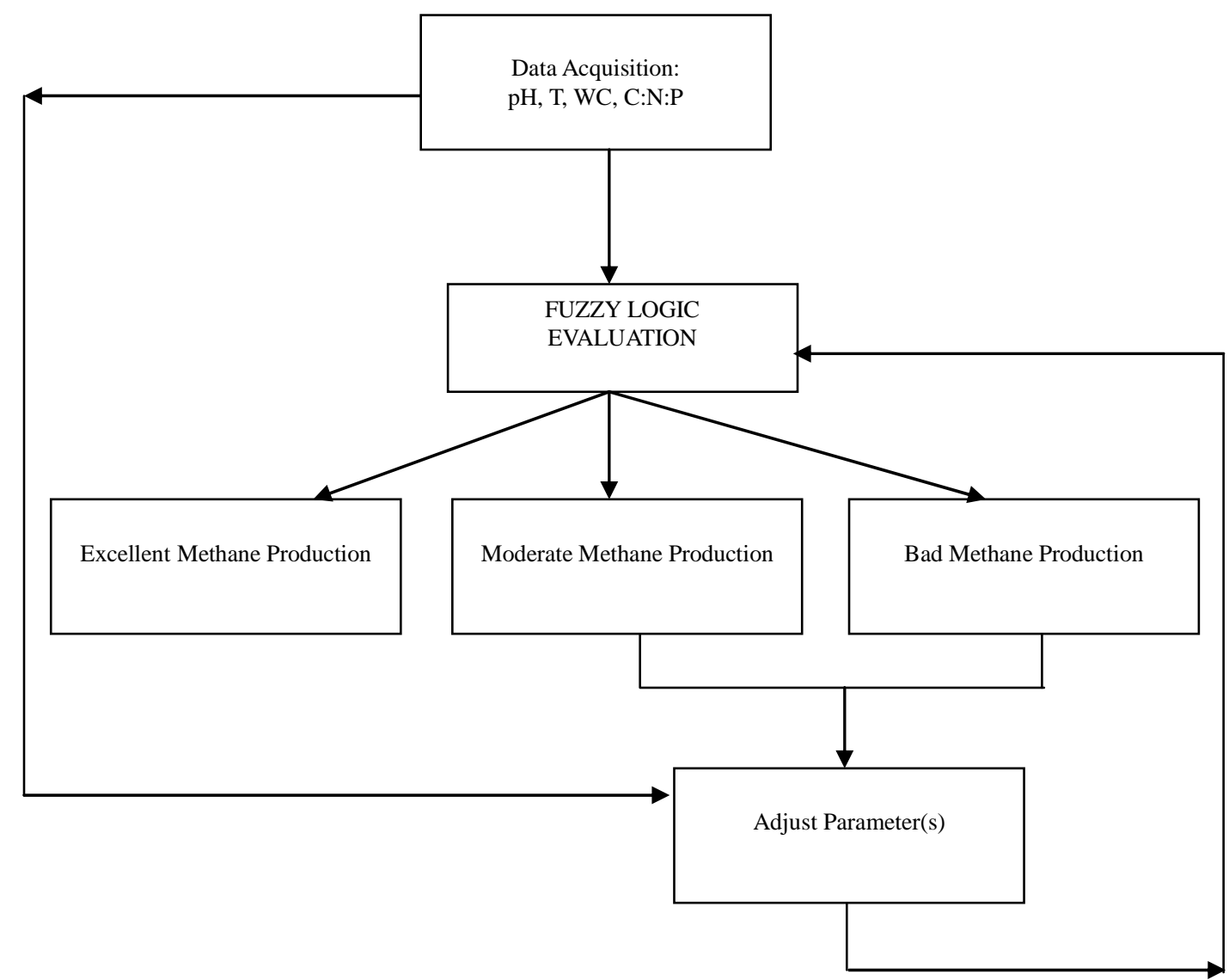

Figure 3. Hierarchy of data acquisition and fuzzy evaluation for methane production quality. 
between moisture and $\mathrm{CH}_{4}$ production may mask relationships between temperature and production, thus it has been difficult to determine the relative importance of these factors. the significant seasonal differences in the magnitude of $\mathrm{CH}_{4}$ production rates at experimental sites with high rates during summer, relative low rates during winter and intermediate rates during spring and autumn. The temperature and moisture are the main reason for the seasonal change of the methane production. The relative importance of moisture and temperature in controlling production rates is difficult because soil temperature and moisture usually vary seasonally in ecosystems. Soil temperatures are usually highest by late summer, but usually reduce soil water. Thus, it is not a straightforward exercise to determine if methane productions rates are affected due to temperature or moisture content or an interaction of both factors.

The fuzzy logic model shown in Figure $\mathbf{4}$ is constructed and trained for two input parameters which are the temperature and the water content as they are variable along the year, and one output for methane production quality with nine if-then rules. The fuzzy inference process entails introducing input, inference process among specified rules, and finally output defuzzification with crisp value (Figure 5). The hierarchy of fuzzy inference system for inputs, rules, and output is shown in Figure 6.

\section{Waste Stabilization in Intelligent MSW Biocells}

The MSW at landfill undergoes biochemical processes that are consisted of four phases: hydrolysis, acidogenesis, acetogenesis, and methanogenesis as shown in Figure 7.

In anaerobic biocells, methane production can be stimulated via carbon dioxide and leachate re-circulation. The biological conversion of $\mathrm{CO}_{2}$ to $\mathrm{CH}_{4}$ is achieved by hydrogenotrophic methanogens that converts $\mathrm{CO}_{2}$ in presence of $\mathrm{H}_{2}$ to $\mathrm{CH}_{4}$. The ratio of $\mathrm{CO}_{2}: \mathrm{H}_{2}$ is an important factor in determining the conversion rate of $\mathrm{CO}_{2}$. The $\mathrm{H}_{2}$

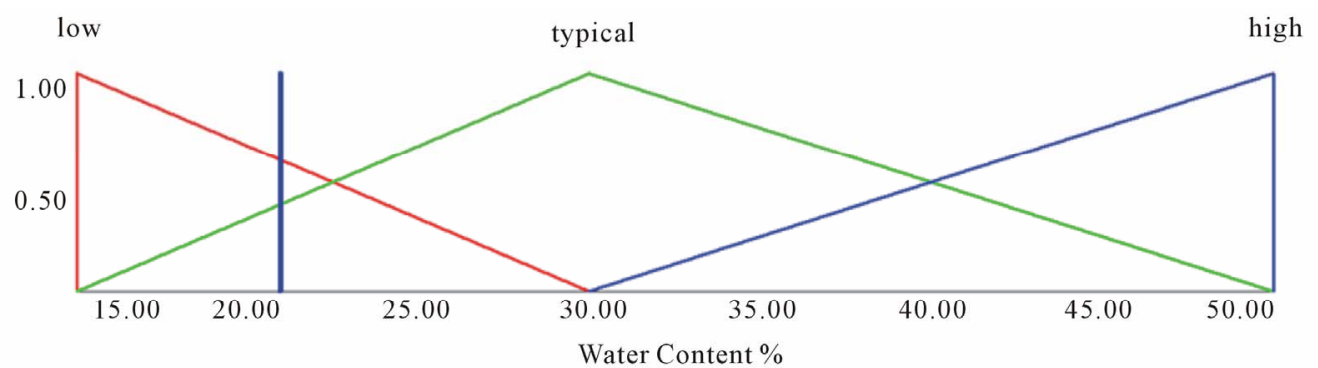

$\mathrm{m} 1: 21.000 \mathrm{~m} 2: 21.000$ am: $0.000 \mathrm{bm}: 0.000$ hm: 1.000 Certainty: 1.000

A

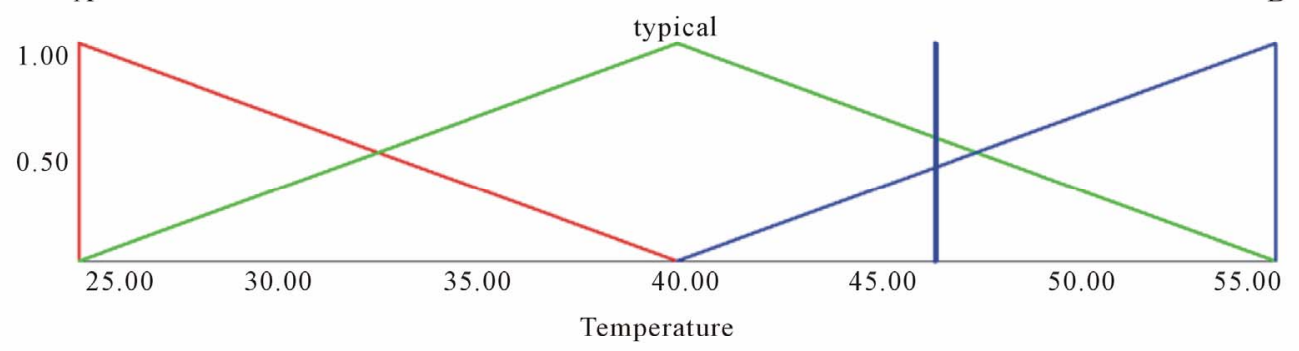

$\mathrm{m} 1: 46.500 \mathrm{~m} 2: 46.500$ am: $0.000 \mathrm{bm}: 0.000$ hm: 1.000 Certainty: 1.000

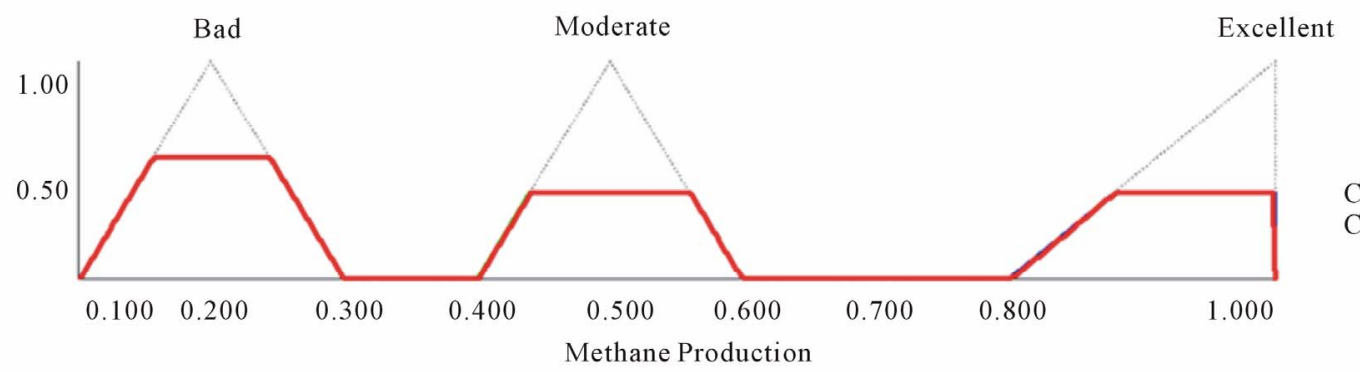

Crisp value: 0.5074

Certainty: 0.000

Inference: MAX.MIN. Defuzzification: COA

Certainty factors

Aggregation: MIN Propagation: MIN Fusion: MAX TNorm: MIN

Certainty Threshold: 0.000

Figure 4. Fuzzy logic model for abiotic factors as input and methane production quality as output. 
1

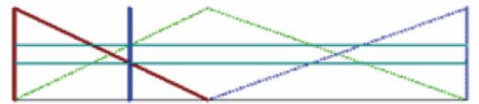

2
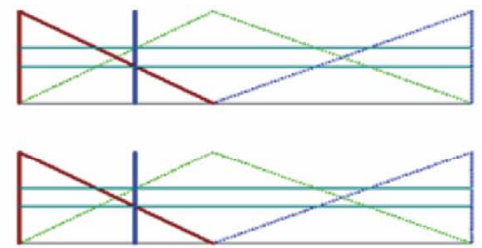

4
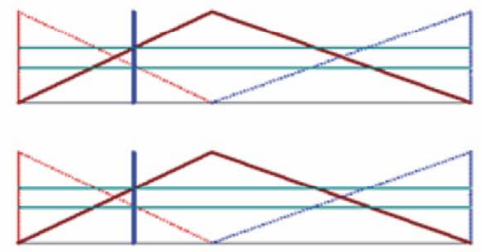

6
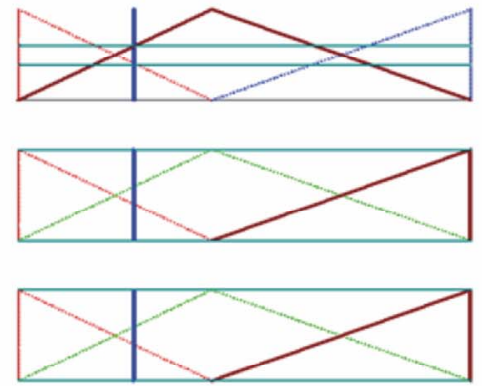

9

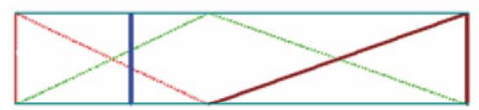

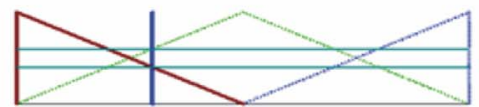
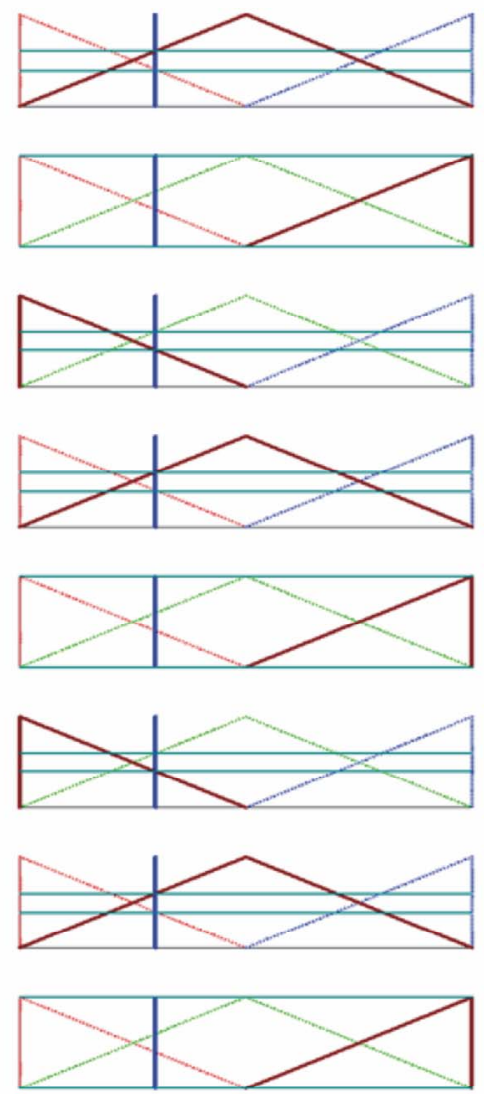
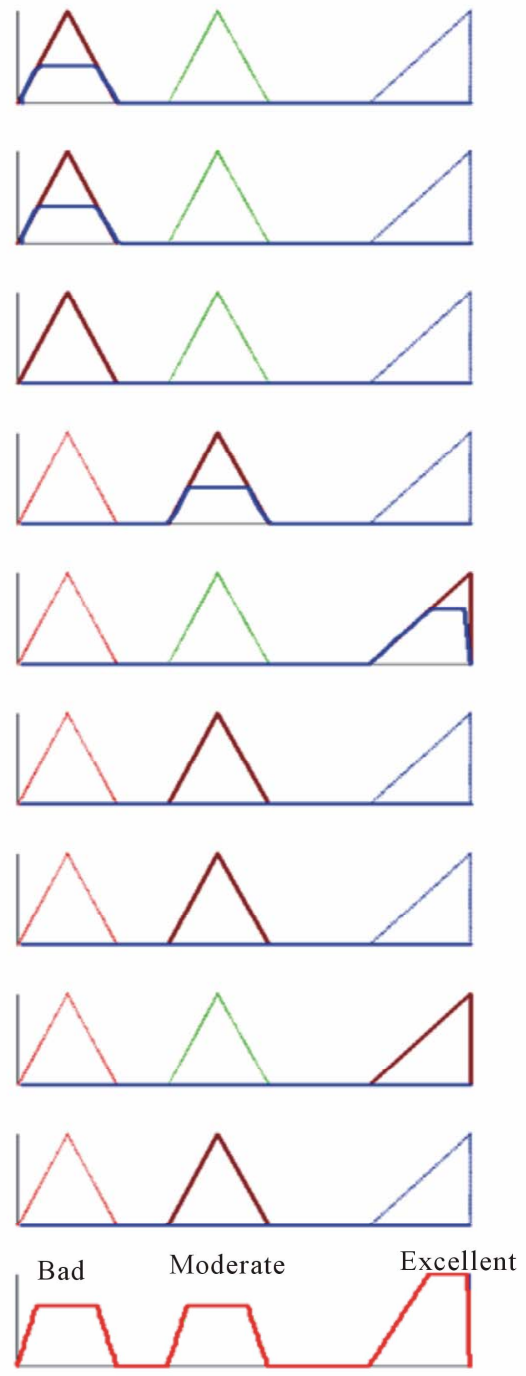

Figure 5. Fuzzy input, inference among rules, and output defuzzification process.

is a product available during acidogenesis and acetogenesis processes. aboitic factors namely: moisture content, temperature, $\mathrm{pH}$, and $\mathrm{C}: \mathrm{N}: \mathrm{P}$ can be controlled via leachate recirculation. However, the technical parameters are set at typical value; $\mathrm{pH}$ range of $6-8$, and $\mathrm{C}: \mathrm{N}: \mathrm{P}$ ratio of 200:4.5:1. The active temperature for methanogenic microorganisms is in the range $30^{\circ} \mathrm{C}-50^{\circ} \mathrm{C}$. The range of moisture content in a typical landfill is 15 to $40 \%$ with a typical average $30 \%$.

\section{Advantages of Intelligent MSW Biocells}

Intelligent MSW biocells is a platform to enhance biogas production and it is flexible to apply $\mathrm{CO}_{2}$ and leachate recirculation which in turn increase waste degradation and methane production. Prospective advantages of our management system include:

- Integrated operation system that combines leachate treatment and enhanced methane production
- Intelligent control on abiotic factors for enhanced methane production

- Intelligent operation system that dynamically maximize methane production

- Biological conversion of recycled $\mathrm{CO}_{2}$ to methane (fuel)

- Fast decomposition and biological stabilization of the waste

- Smooth and fast transfer of biogas from waste to the permeable membranes

- Ability of biogas separation using selective hydrophobic membranes

- Ability to achieve sustainable green bio-fuel reactors (biocells)

\section{Conclusion}

Intelligent MSW biocell aims to enhance anaerobically methane production via technical and intelligent processes. 


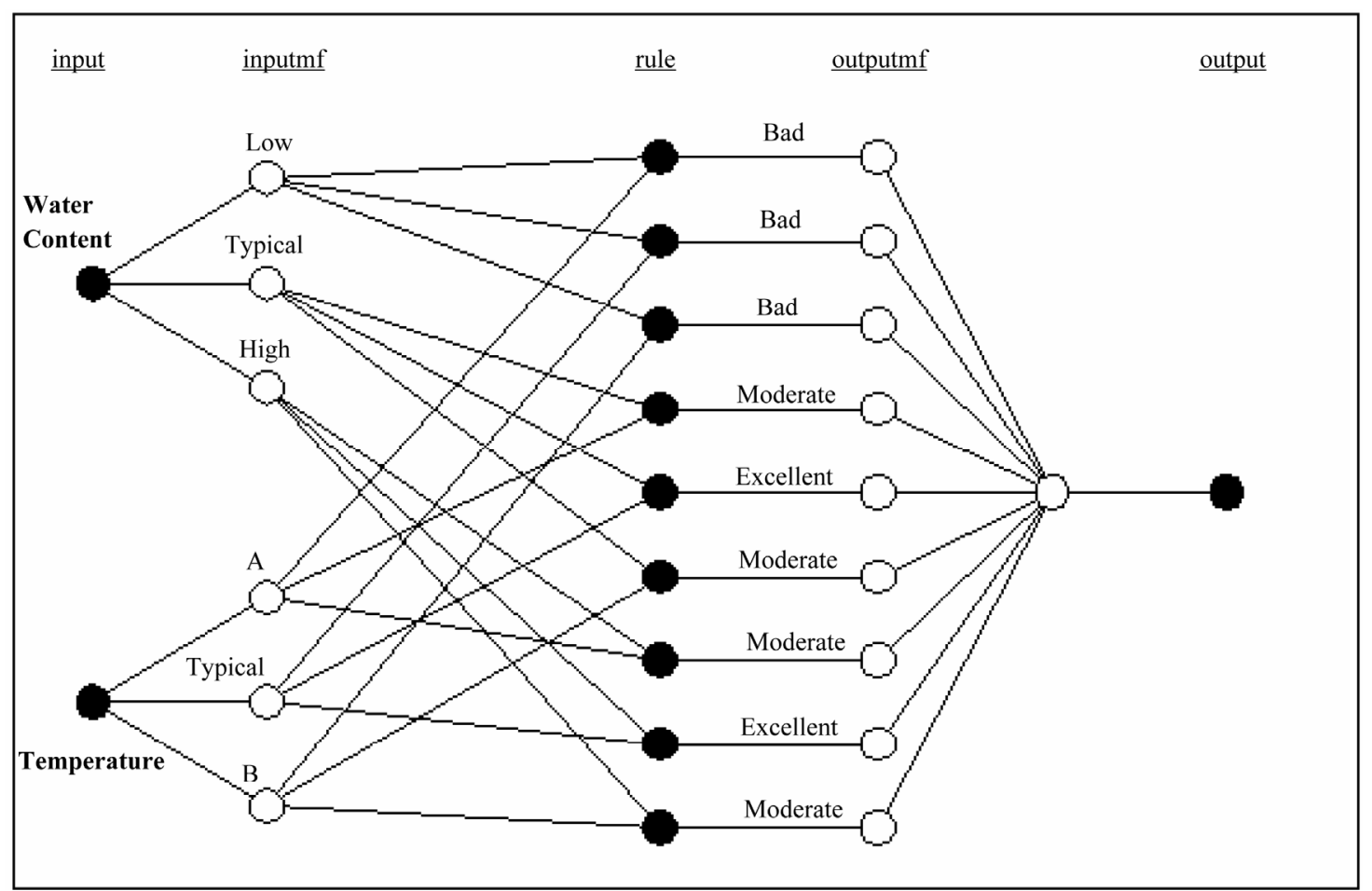

Figure 6. Fuzzy inference system for inputs, rules, and output.

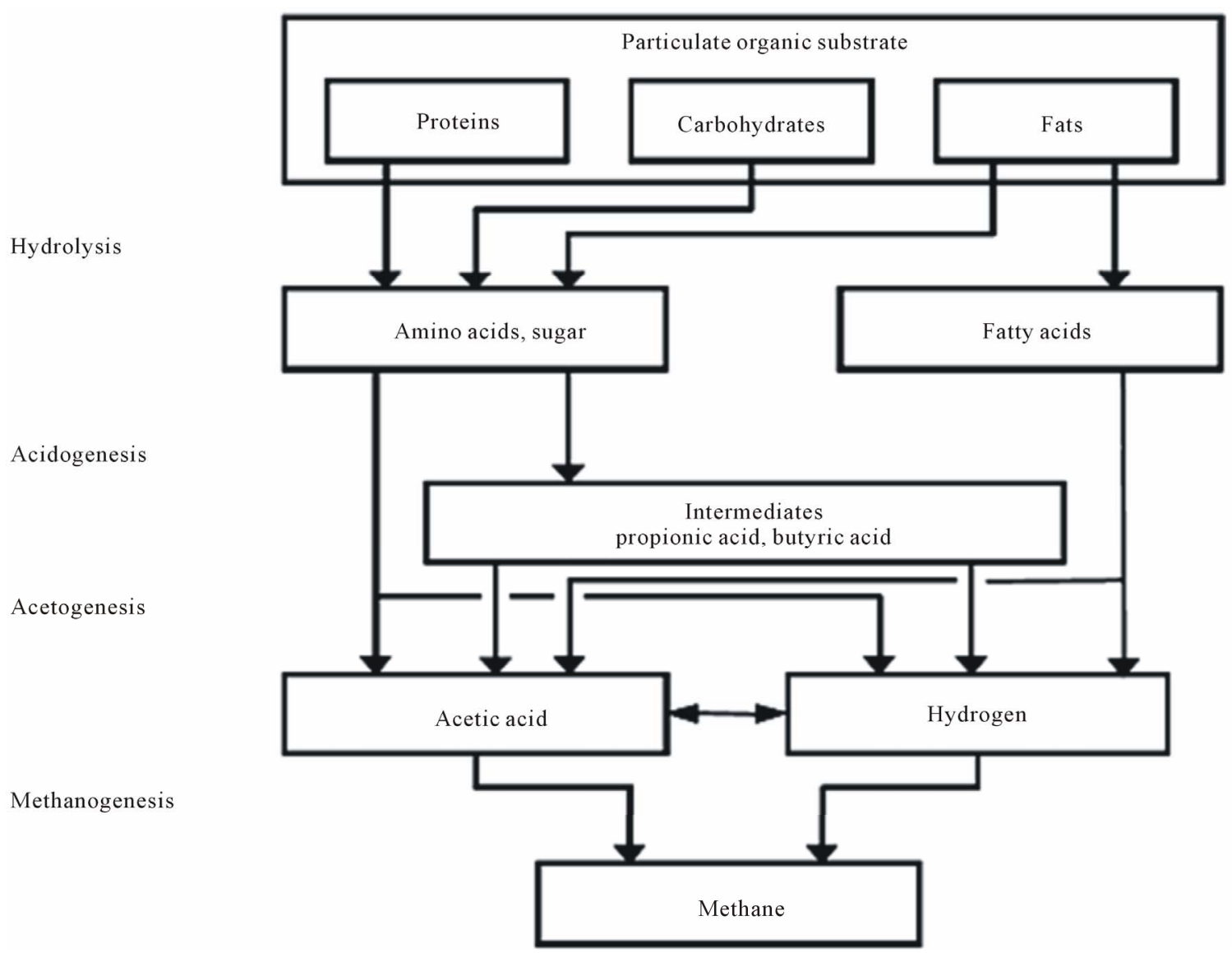

Figure 7. Anaerobic biodegradation for solid waste [16]. 
The technical processes entail leachate and carbon dioxide recirculation. The re-circulated leachate is controlled via fuzzy intelligent system that controls values of abiotic factors such as $\mathrm{C}: \mathrm{N}: \mathrm{P}, \mathrm{pH}$, temperature, and moisture content. Carbon dioxide is being re-circulated to convert it biologically to methane by hydrogenotrophic methanogens. The selective hydrophobic membranes are used to separate biogas and to achieve smooth and fast transfer of biogas from waste to the storage, the approach of this research is deemed as promising sustainable green bio-technology.

\section{Acknowledgements}

The Deanship of Research and Deanship of Engineering in Jerash University is gratefully acknowledged.

\section{REFERENCES}

[1] T. Ishigaki, M. Yamada, M. Nagamori, Y. Ono and Y. Inoue, "Estimation of Methane Emission from Whole Waste Landfill Site Using Correlation between Flux and Ground Temperature,” Environmental Geology, Vol. 48, No. 7, 2005, pp. 845-853. doi:10.1007/s00254-005-0008-0

[2] J. C. Stern, J. Chanton, T. Abichou, D. Powelson, L. Yuan, S. Escoriza and J. Bogner, "Use of Biologically Active Cover to Reduce Landfill Methane Emissions and Enhance Methane Oxidation,” Waste Management, Vol. 27, No. 9, 2007, pp. 1248-1258. doi:10.1016/j.wasman.2006.07.018

[3] K. Wang-Yao, S. Towprayoon, C. Chiemchaisri, S. H. Gheewala and A. Nopharatana, "Seasonal Variation of Landfill Methane Emission from Seven Solid Waste Disposal Sites in Central Thailand," The 2nd Joint International Conference on Sustainable Energy and Environment (SEE 2006), Bangkok, 21-23 November 2006.

[4] P. M. Czepiel, J. H. Shorter, B. Mosher, E. Allwine, J. B. McManus, R. C. Harriss, C. E. Kolb and B. K. Lamb, "The Influence of Atmospheric Pressure on Landfill Methane Emissions,” Waste Management, Vol. 23, No. 7, 2003, pp. 593-598. doi:10.1016/S0956-053X(03)00103-X

[5] R. N. Kinman, D. L. Nutini, J. J. Walsh, W. G. Vogt, J. Stamm and J. Rickabaugh, "Gas Enhancement Techniques in Landfill Simulators," Waste Management and Research, Vol. 5, 1987, pp. 13-25.

[6] D. R. Reinhart and A. B. L. Yousfi, "The Impact of Leachate Recirculation on Municipal Solid Waste Landfill Operating Haracteristics," Waste Management and Research, Vol. 14, 1996, pp. 337-346.

[7] D. R. Reinhart and T. G. Townsend, "Landfill Bioreactor Design and Operation,” Lewis Publishers, Boca Raton, 1998.

[8] H. Zhang, P. He and L. Shao, "Methane Emissions from MSW Landfill with Sandy Soil Covers under Leachate
Recirculation and Subsurface Irrigation," Atmospheric Environment, Vol. 42, No. 22, 2008, pp. 5579-5588.

doi:10.1016/j.atmosenv.2008.03.010

[9] T. H. Christensen, P. Kjeldsen and B. Lindhardt, "GasGenerating Processes in Landfills,” In: T. H. Christensen, R. Cossu and R. Stegmann, Eds., Landfilling of Waste: Biogas, E \& FN Spon, London, 1996, pp. 25-50.

[10] A. Isci and G. N. Demirer, "Biogas Production Potential from Cotton Wastes,” Renewable Energy, Vol. 32, No. 5, 2007, pp. 750-757. doi:10.1016/j.renene.2006.03.018

[11] P. T. Williams, "Waste Treatment and Disposal," 2nd Edition, John Wiley \& Sons Ltd, Chichester, 2005, pp. 171-244. doi:10.1002/0470012668.ch4

[12] N. M. Naranjo, J. A. Meima, A. Haarstrick and D. C. Hempel, "Modelling and Experimental Investigation of Environmental Influences on the Acetate and Methane Formation in Solid Waste,” Waste Management, Vol. 24, No. 8, 2004, pp. 763-773. doi:10.1016/j.wasman.2004.04.006

[13] K. R. Gurijala, P. Sa and J. A. Robinson, "Statistical Modeling of Methane Production from Landfill Samples,” Applied and Environmental Microbiology, Vol. 63, 1997, pp. 3797-3803.

[14] K. Sormunen, M. Ettala and J. Rintala, "Detailed Internal Characterization of Two Finnish Landfills by Waste Sampling," Waste Management, Vol. 28, No. 1, 2008, pp. 151-163. doi:10.1016/j.wasman.2007.01.003

[15] D. Tecle, J. Lee and S. Hasan, "Quantitative Analysis of Physical and Geotechnical Factors Affecting Methane Emission in Municipal Solid Waste Landfill," Environmental Geology, Vol. 56, No. 6, 2008, pp. 1135-1143. doi:10.1007/s00254-008-1214-3

[16] Anaerobic Biodegradation for Solid Waste, 2012. http://www.wtert.eu/default.asp?Menue=13\&ShowDok=1 2\#AcidogenesisAcidogenesis

[17] Q. Ahmad, E. Maria and J. Iwona, "Investigation and Fuzzy Regime for Biogas Transport in Hydrophobic Permeable Polymer," Annual Meeting of the North American: Fuzzy Information Processing Society, 3-6 June 2006, pp. 25-30.

[18] Q. Ahmad, E. Maria and J. Iwona, "Intelligent Fuzzy Control for Biogas in Hydrophobic Polymer System," IEEE International Symposium on Industrial Electronics, Vol. 1, 2006, pp. 252-256.

[19] Q. Ahmad, E. Maria and J. Iwona, "Intelligent Novel Solid Waste Management System (QEJ Bricks Biocell Approach)," Hypothesis, Vol. 8, No. 1, 2010, pp. 1-14.

[20] Q. Ahmad, "Root Analogous Solid Waste Management System (RA-MSW for Biocells)," Journal of environmental Protection, Vol. 3, No. 8, 2010, in press.

[21] Q. Ahmad, E. Maria and J. Iwona, "Investigation of Biogas Transport in Hydrophobic Permeable Medium for Biocells," Journal of Solid Waste Technology and Management, in press. 